\title{
La escritura de los jóvenes en los chats en el siglo XXI
}

\author{
Sonia SÁNCHEZ MARTíNEZ \\ Universidad Camilo José Cela \\ smartinez@ucjc.edu
}

Recibido: 24 de mayo de 2014

Aceptado: 29 de octubre de 2015

\section{RESUMEN}

El presente ensayo versa sobre la conversación escrita que mantienen los jóvenes hoy en sus chats. Se tratan las diferentes variedades lingüísticas. La escritura de los chats equivale a una conversación: los textos escritos se convierten en textos orales, las conversaciones se transcriben y las normas lingüísticas se rompen. Esto no significa que los jóvenes no sepan cuáles son, pero en los chats, no les interesan.

Palabras clave: Chat, normas lingüísticas, textos orales, textos escritos.

How young people write in chats in the $21^{\text {st }}$ century

\begin{abstract}
This essay looks at the written languages that young people use in their line conversations currently. It reviews the linguistic variations. Online conversations carry an equal significant to oral conversations but linguistics rules are broken when conversations are transcribed. Whilst young people may be aware of the linguistics rules, during online written conversations they ignored them.
\end{abstract}

Key words: Text messaging, language rules, transcribed, written texts.

L'écriture des jeunes d'aujourdui dans leurs chats au XXIème siècle

\section{RÉSUMÉ}

Cet essai étudie la conversation écrite que les jeunes d'aujourdhui entretiennent dans leurs chats.Les différentes variantes linguistiques sont abordées. L'ecriture des chats équivaut à une conversation: les textes écrits se transforment en textes parlés, les conversations se transcrivent et les règles lingüistiques ne sont pas respectées. Cela ne veut pas dire que les jeunes ne connaissant pas quelles ces règles, mais lors des chats, ils ne les appliquent pas.

Mots-clés: Chat, règles linguistiques, textes oraux, textes ecrits.

SUMARIO: 1. Introducción; 2. La escritura de los jóvenes en los chats; 3. El chat en el aula; 4. Conclusión; 5. Bibliografía. 


\section{INTRODUCCIÓN}

Para el presente trabajo hemos contado, por un lado, con un grupo de jóvenes, diecinueve en total, que tienen entre 18 y 20 años. Sus cualidades idiosincrásicas son muy parecidas y, por lo tanto, relevantes por las características propias de las variedades lingüísticas que tratamos en estas páginas. Este grupo de jóvenes es de raza blanca, de clase social media, son universitarios, viven en la misma zona de Madrid capital y han estudiado enseñanza secundaria y bachillerato en el mismo centro. Me apoyo, por otro lado y para contrastar algunas de las ideas que expongo de aquí en adelante, en el vocabulario de algunos adolescentes, alumnos de secundaria y de bachillerato, que viven en la zona oeste de Madrid y estudian en el mismo instituto.

La investigación se ha dividido en dos partes. La primera se inició a partir de la apertura de chat de la aplicación WhatsApp. Durante tres meses seguí sus conversaciones y no participé. Ellos escribieron como si yo no estuviera, excepto cuando necesitaba que aclararan mis dudas sobre las redes sociales, los chats o las abreviaturas ("LOL XD", que significa "jajaja y una carita feliz"). Sus conversaciones siempre fueron improvisadas e informales y no tuvieron en cuenta mi presencia a la hora de hablar entre ellos. La segunda se preparó en las aulas anotando las expresiones orales y siguiendo las conversaciones en un chat de WhatsApp, certificando que las mismas expresiones utilizadas oralmente eran las mismas que escribían en esos chats. Una vez terminado este proceso, abrimos un foro tratando temas relacionados con la asignatura de Lengua Castellana y Literatura y publicamos sus redacciones en un blog, para comprobar que los mismos alumnos que escriben de una manera para relacionarse con sus amigos, compañeros o novios, escriben de otra al realizar trabajos académicos.

En los años que llevo impartiendo docencia, he comprobado que los jóvenes abrevian palabras en sus redacciones, apuntes o exámenes, pero no comenten los errores ortográficos que se comenten en un SMS o en un chat como el WhatsApp, o en Instagram o en Twitter. Su forma de escribir pertenece a su jerga, como signo de rebeldía frente a la norma establecida, que desaparecerá cuando se conviertan en adultos y adopten la lengua común. Como ya sabemos, la jerga juvenil es voluble, inconstante y efímera, cada día aparece vocabulario nuevo ("en plan de...", "me renta", "fichote", etc.) que puede morir en el mismo momento en que nace o puede perdurar algo más en el tiempo. Los jóvenes no tienen reglas ortográficas en el WhatsApp, no les interesa ni ponen atención, prefieren la inmediatez del mensaje; por lo tanto, no está en sus intereses escribir con propiedad.

\section{LA ESCRITURA DE LOS JÓVENES EN LOS CHATS}

El teléfono móvil es utilizado por un gran porcentaje de la población, independientemente del sexo o de la edad. En él incluimos la agenda, el reloj, los procesadores de textos, los juegos, almacenamos documentos, los enviamos a la "nube" y bajamos docenas de aplicaciones que forman parte de nuestro día a día. Deja de ser 
esencial como teléfono y se hace imprescindible para los SMS y los WhatsApp. Existe una diferencia singular entre los mensajes de WhatsApp que escriben los jóvenes dependiendo, no solo de la edad, sino del lugar de nacimiento y su estatus social. Los interlocutores son muy importantes pues depende de quién sea el descodificador del mensaje de WhatsApp, este estará escrito con más o menos corrección. Estos jóvenes tienen la capacidad para cambiar de registro, tienen movilidad diafásica; como sabemos no todos los hablantes la poseen y se adquiere en función de una serie de variantes, entre las que la formación ocupa un lugar importante. En el momento en el que yo participo en el chat y hago preguntas, ellos deciden en qué situaciones es correcto utilizar un determinado registro y en cuáles inapropiado. Sin darse cuenta, ellos reconocen algunos de los factores que intervienen en la configuración de un registro, como la relación que nos une a ambos pues somos profesoraalumnos. La sociolingüística nos habla a este respecto de la acomodación, según la cual fijándonos en los rasgos más sobresalientes del mensaje de nuestros interlocutores, acomodamos el propio.

Conocemos que nunca dos hablantes hacen uso exactamente del mismo código en un sistema determinado, sino que los actos de habla cambian los unos con respecto a los otros. Nos hemos ido adaptando a la lengua conforme hemos ido avanzando en nuestra evolución. Así nos encontramos con los mensajes tecnológicos, con la escritura instantánea que varía poco, casi siempre, del habla. Este tipo de comunicación genera una nueva forma de interacción que resulta interesante desde el punto de vista lingüístico. Todos las conversaciones que se leen en un WhatsApp producen actos de habla, incluso el acto locutivo, y aunque no exista el acto fónico, sí existe el fático y el rético pues se emiten secuencias gramaticales estructuradas y con sentido determinado. El acto ilocutivo y el acto perlocutivo predominan en este tipo de comunicación escrita: el acto ilocutivo en su intención comunicativa de prometer o de afirmar; y el acto perlocutivo en las reacciones que provocan las emisiones en el interlocutor como la función de convencer o la de calmar. Este canal, el chat, lleva implícito su carácter dialógico. Al igual que una conversación oral es bilateral, directa e inmediata y su receptor es concreto; sin embargo, cumple también las características de los textos escritos puesto que no desaparece en el mismo instante de su producción y existe la posibilidad de volver hacia atrás y volver a leer el mensaje puesto que conserva la misma forma en la que ha sido producido. Carece, eso sí, al ser comunicación escrita del lenguaje no verbal, que se suple con los emoticonos. Estos también han evolucionado, y ya de los emoticonos primeros, aquellos en los que el ingenio y el teclado eran los que mostraban la cara alegre en una conversación, por ejemplo :-) o triste :( que se convierten ahora en caritas (), : $:$. Los emoticonos actuales son más elaborados y abundantes pero, tal vez, menos ingeniosos. Ahora hay aplicaciones para descargar emoticonos que se incluyen en los teclados de los móviles o de las tabletas y sirven para enviar cualquier mensaje sin necesidad de palabras. Sirva como ejemplo: 

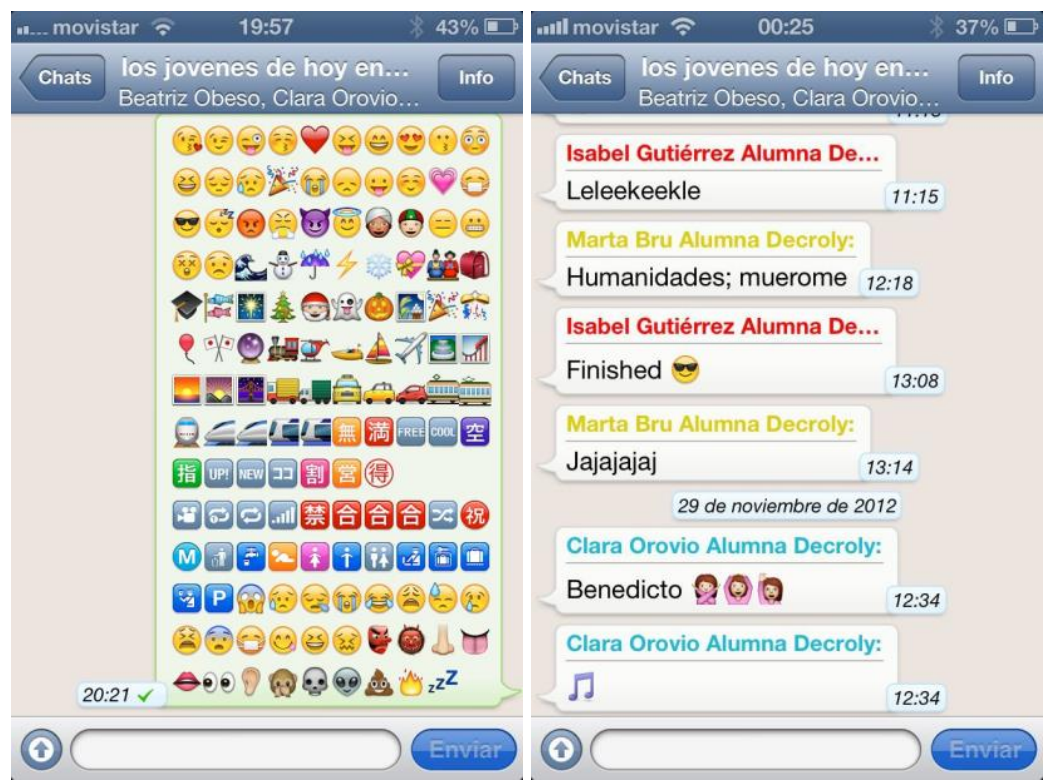

\begin{tabular}{|c|c|c|}
\hline ...movistar 尺 & & $36 \%$ प् \\
\hline $\begin{array}{l}\text { Chats los jovenes de hoy e } \\
\text { Beatriz Obeso, Clara Oro }\end{array}$ & $\begin{array}{l}\text { en... } \\
\text { ovio... }\end{array}$ & Info \\
\hline Clara Orovio Alumna Decroly: & & \\
\hline $\begin{array}{l}\text { Tengo un } 6 \text { que es lo que } \\
\text { se lleva ahoraaaa }\end{array}$ & 23:12 & \\
\hline Isabel Gutiérrez Alumna De... & & \\
\hline Es un honor & 23:12 & \\
\hline Clara Orovio Alumna Decroly: & & \\
\hline 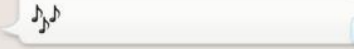 & 23:13 & \\
\hline Isabel Gutiérrez Alumna De... & & \\
\hline Joder & & \\
\hline Los chinos & & \\
\hline $\begin{array}{l}\text { Hay un monton de iconos } \\
\text { con muvins chinas }\end{array}$ & & \\
\hline 指 & & \\
\hline 空 & 23:13 & \\
\hline
\end{tabular}

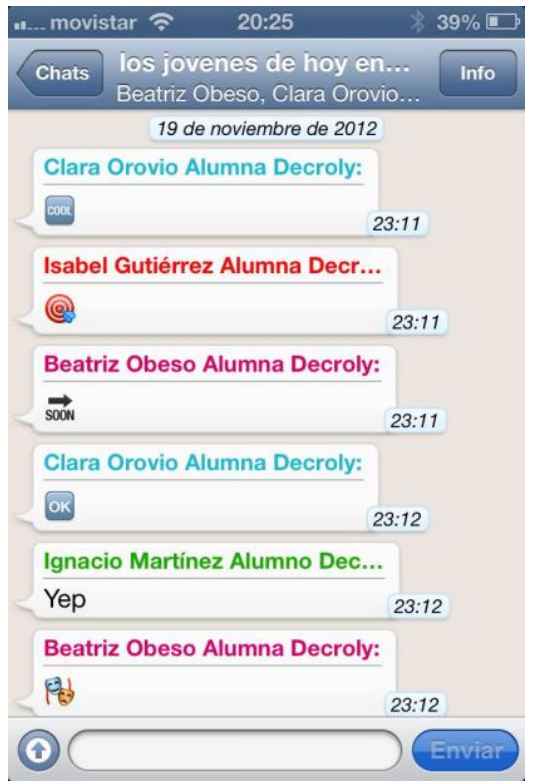


En ocasiones, como vemos en las imágenes a continuación, la presencia de anglicismos e incluso de palabras o frases en el idioma anglosajón caben en sus discursos y a ninguno de los participantes le extraña y siguen manteniendo el diálogo. Las abreviaturas ("Eske", "tngo", "xq") y las faltas de ortografía pueden expresar problemas en el ámbito académico, como ya hemos señalado, pero las nuevas tecnologías no empobrecen la forma del discurso, lo empobrecen la falta de estudio y la falta de lectura. Por supuesto, esas abreviaturas no solo suceden en nuestra lengua ("LOL"); en inglés se utilizan códigos numéricos combinados con grafías para abreviar aún más: 4u (for you), W2tlk? (Want to talk?) construcciones que han adoptado nuestros jóvenes.

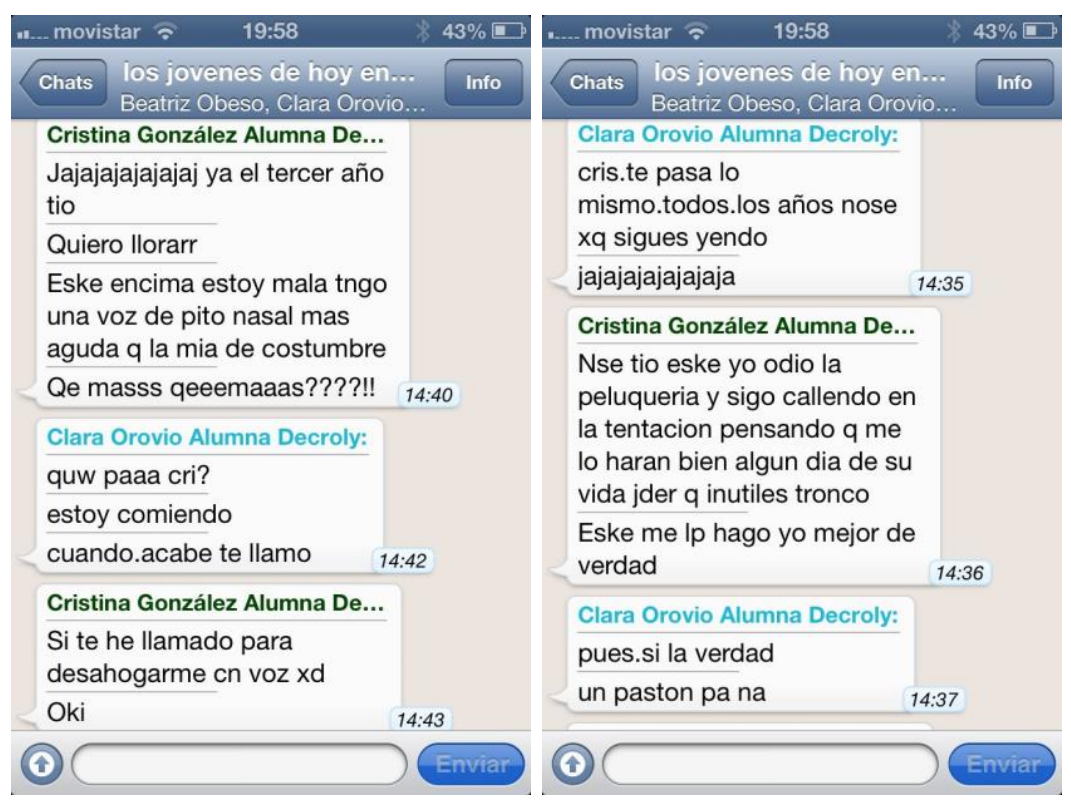




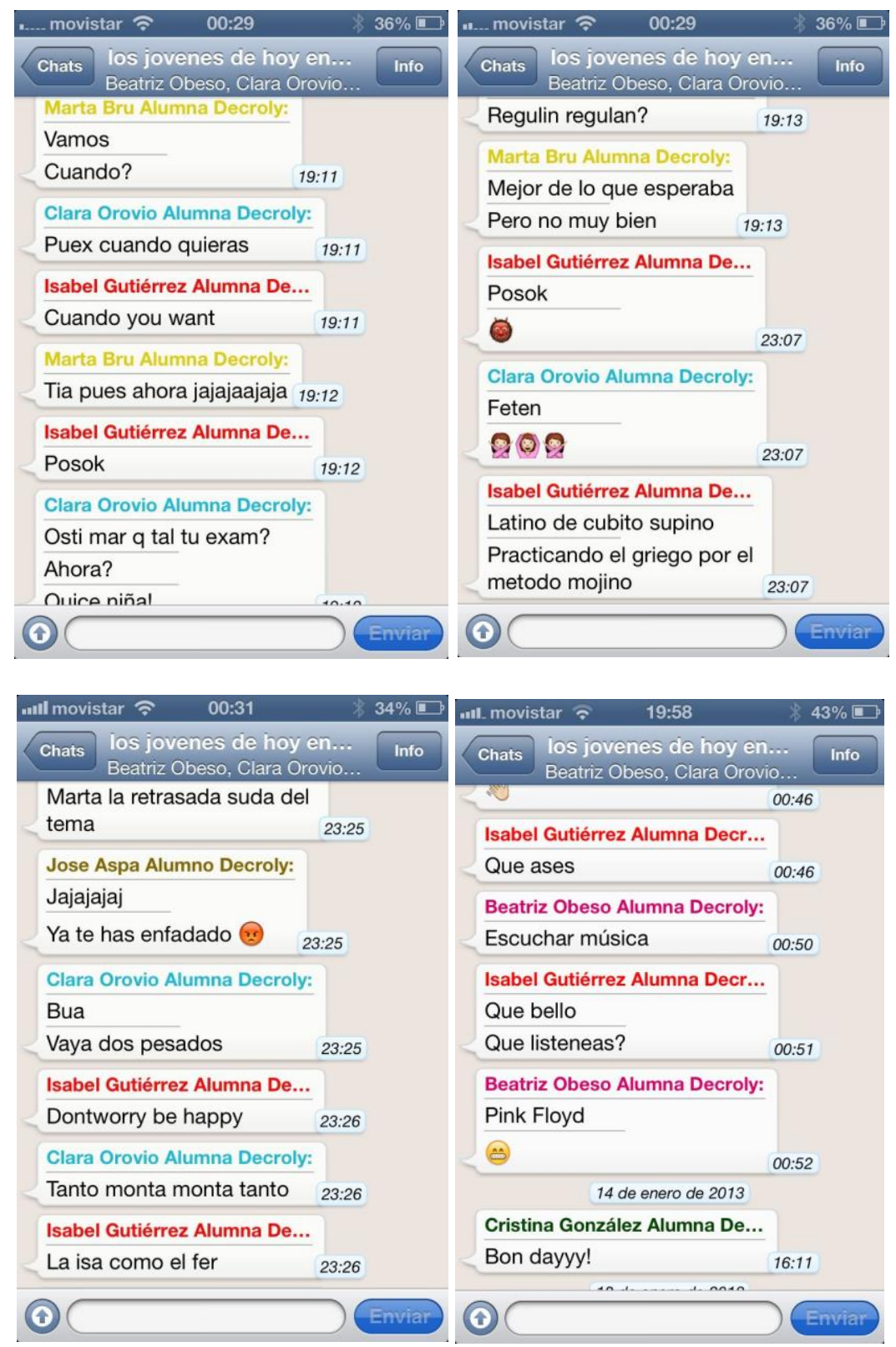




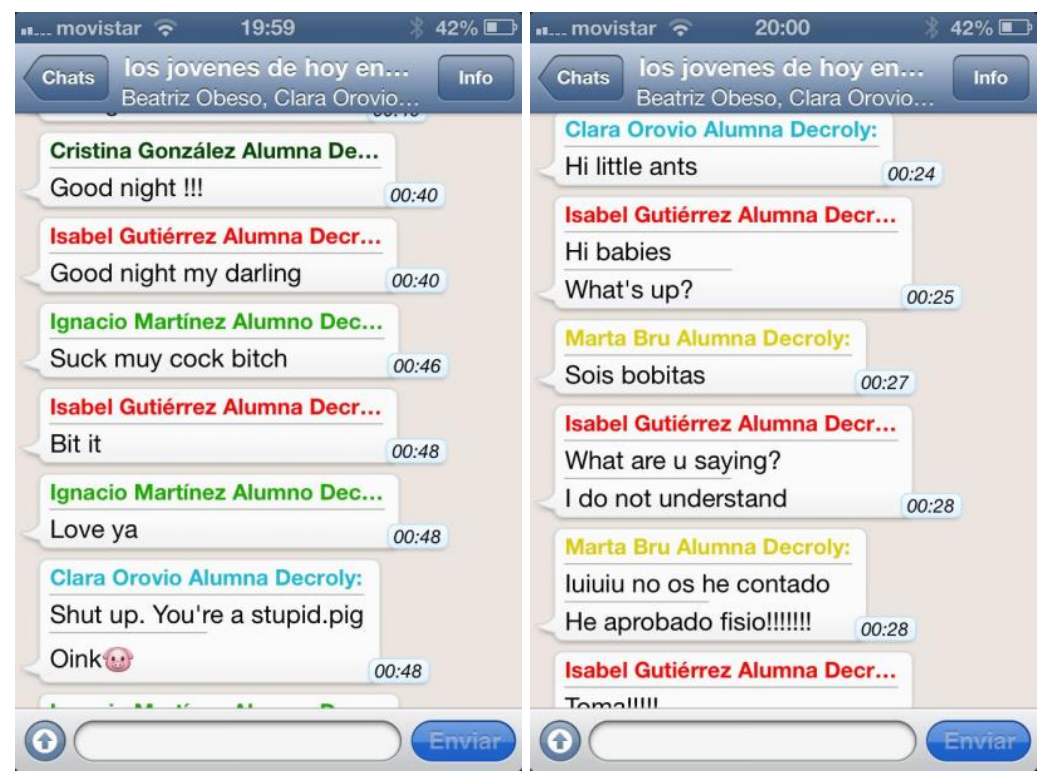

Algo muy interesante que hemos observado es que cuando los jóvenes tenían únicamente 160 caracteres en sus SMS abreviaban de tal manera que se suprimían las vocales, empleando la economía lingüística, y escribían palabras como:

$$
\begin{aligned}
& \text { "amg" por "amigo" } \\
& \text { "kien" por "quién o quien" } \\
& \text { "qantos" por "cuántos o cuantos" }
\end{aligned}
$$

o mensajes como:

"ted-" por "te echo de menos"

"t tien lokta" por "te tiene loquita"

"es nbidioso" por "es envidioso"

"ya toy aki" por "ya estoy aquí"

"qrs ablar?" por "¿Quieres hablar?"

"q tl stas wapa?" por "Qué tal estás guapa?

"xfa, ns bmos dspues d kls" por "Por favor, nos vemos después de clase"

"Qtal? e vst a juan st smn no sldr el sbad q aces t?” por "¿Qué tal? He visto a Juan esta semana, no saldrá el sábado. ¿Qué haces tú?" 
Estos mensajes lo que hacían era que fueran códigos ininteligibles para los adultos, solo ellos, los adolescentes, acostumbrados a quitar las vocales de sus mensajes eran capaces de descodificarlos. En sus mensajes, evitaban la información superflua e inútil, los espacios entre las palabras y aparecían signos matemáticos: "nopued+", "ted-" o "m kdare studnd asta ls 9 +o-", por ejemplo.

Desde la llegada del WhatsApp la escritura de adolescentes y jóvenes se ha trasformado, y aunque las palabras se escriben casi siempre completas, siguen escribiendo sin acentos; no obstante, algunos adolescentes continúan suprimiendo vocales o consonantes en algunas palabras o expresiones y escriben, por ejemplo: "klk", "tt" o "ntr", que significa "que lo que", "tío, colega" o "no te rayes".

En los ejemplos que se muestran a continuación, los alumnos explican cuándo abrevian y por qué, normalmente, al escribir sus mensajes y estas son algunas de las respuestas:

"Yo no hablo con abreviaturas, solo cuando mando sms para no pagar más, lo que me pasa a mi es que no manejo los táctiles y escribo fatal pero no aposta".

"Yo intento abreviar por comodidad y depende de con quien hable abrevio mas o menos en función de si me va a entender XD"

"Siempre se intenta escribir bien, pero cuando se tiene prisa, estas agobiado o por pereza se abrevia en cosas típicas como el "q" o quitando vocales. Siempre se abrevia de las modo que sabes que te van a entender".

"Y depende de la falta de ortografía me da igual o no cometerla, por ejemplo tildes, ola sin h o cosas así me da igual".

"Yo si es con mi madre prefiero escribir bien. Pero en general me da igual cometer faltas sinceramente".

"Yo intento no cometer faltas ni abreviar, antes con los sms si lo hacia porque a mas letras mas dinero pero ahora que da igual no lo hago, creo que por dos o tres letras más quedas bien escribas a quien escribas". 


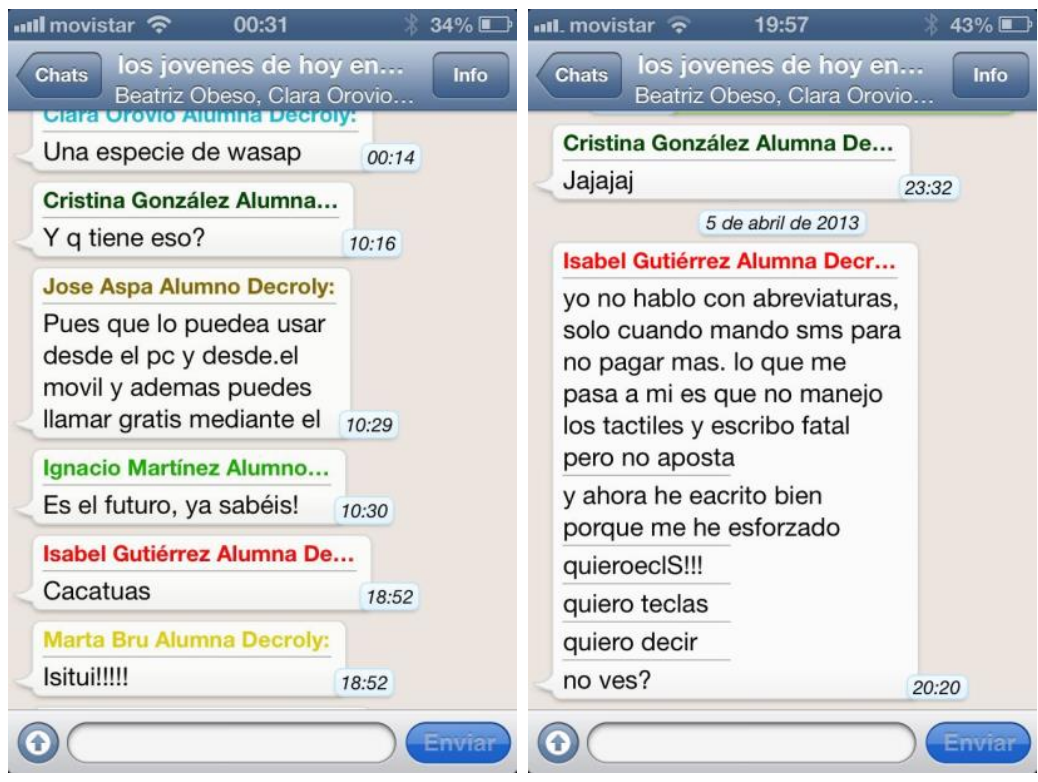

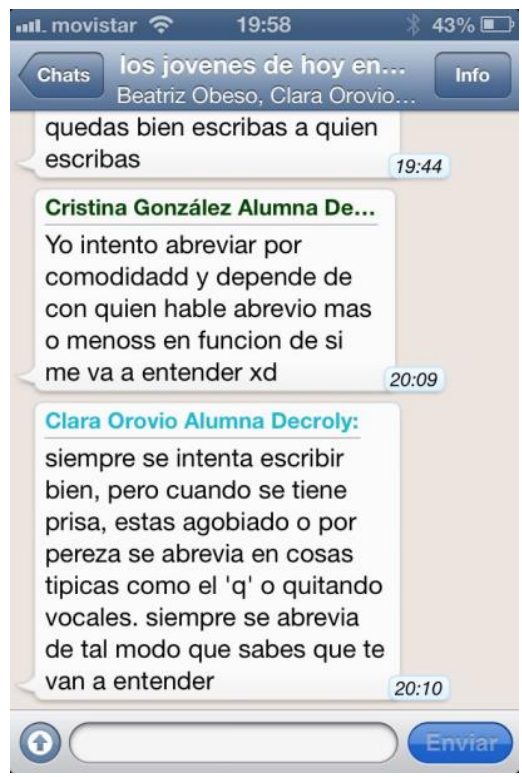




\begin{tabular}{|c|c|c|}
\hline ntll. movistar ₹ & $\$ 48$ & $3 \% \square$ \\
\hline $\begin{array}{l}\text { Chats los jovenes de hoy en. } \\
\text { Beatriz Obeso, Clara Orovio }\end{array}$ & o. & Info \\
\hline $\begin{array}{l}\text { vocales. siempre se abrevia } \\
\text { de tal modo que sabes que te } \\
\text { van a entender }\end{array}$ & $20: 10$ & \\
\hline Cristina González Alumna De... & & \\
\hline $\begin{array}{l}\text { Y depende de la falta de la } \\
\text { falta de ortografia me da igual } \\
\text { o no cometerla, por ejemplo } \\
\text { tilder ola sin h o cosas asi me } \\
\text { da igual }\end{array}$ & $20: 11$ & \\
\hline +34616950471 - Irenito... & & \\
\hline $\begin{array}{l}\text { Yo si es con mi madre } \\
\text { prefiero escribir bien }\end{array}$ & & \\
\hline Pero en general & & \\
\hline $\begin{array}{l}\text { Me da igual cometer faltas } \\
\text { sinceramente }\end{array}$ & & \\
\hline$X d$ & :15 & \\
\hline
\end{tabular}

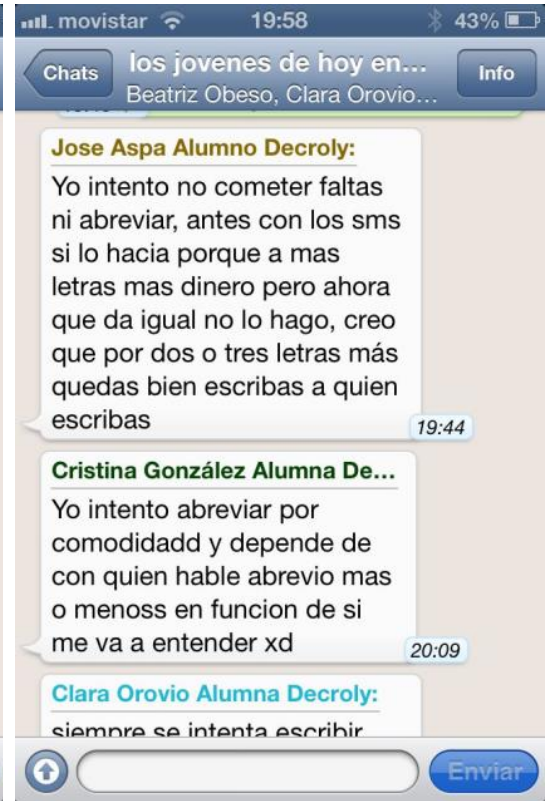

Fijémonos en las formas gramaticales que emplean y en el porqué de que no se preocupen por ellas, en la acentuación, en las abreviaturas, en la falta de signos de puntuación, en escribir un único signo de interrogación o admiración al final de la oración o poner varios signos de admiración o interrogación. Todo ello se debe, fundamentalmente, a que saben que el receptor tiene su misma edad y que sabrán descodificar el mensaje sin necesidad de que su escritura sea la correcta; además de la obligación que se crean ellos mismos de teclear deprisa, pues sus mensajes han de ser instantáneos y les urge comunicar a su igual lo que ven, lo que oyen y lo que sienten en ese momento. Si estos mismos alumnos escriben en clase en una hoja lo mismo que han escrito en el chat, se preocuparán de no cometer errores ortográficos (aunque puedan cometerlos por la ignorancia de las propias reglas) pues la persona que leerá el mensaje será el profesor.

Si analizamos la morfología de las frases, por ejemplo: la utilización de los verbos, no se emplean los compuestos ni las perífrasis verbales; la abundancia de adjetivos aunque siempre repetitivos e inventados como "reguapo", "guay" "(mola) mazo", "to flama (todo guapo)", "toy (pringado)". Si prestamos atención a la sintaxis, no existen oraciones complejas, solo simples o frases y presentan muletillas del lenguaje oral como "venga", "vamos" o "sí, hombre". Todo ello puede mostrar una rebeldía contra la norma linguiística; pues, es evidente que a los jóvenes de quince años no les interesan las normas y que solo tienen la urgencia de comunicarse con su amigo, su novio o su colega. Asimismo resulta cierto que se diferencian de los de dieciocho, de los de veinticinco y de los adultos. Cada grupo generacional tiene una 
forma particular de hablar que les separa de sus antecesores, aunque tengan rasgos y vocabulario común. No hemos de olvidar que grupos de personas de treinta, cuarenta e incluso cincuenta siguen utilizando, por ejemplo, la palabra "tío" en su vocabulario con los grupos generacionales afines. Los jóvenes buscan sus diferencias no solo en el lenguaje, lo hacen en su forma de pensar, de actuar, de vestirse y de vivir. A medida que vamos envejeciendo todo ello cambia y nos volvemos más cautelosos. En el factor edad, sabemos que en las sociedades modernas y cosmopolitas, las diferencias lingüísticas generacionales marcan diferentes sociolectos. Existe una tendencia a la constante creación de una terminología propia y nueva por parte de las generaciones más jóvenes: "flipas", "petado", "pillar", "pirarse la pinza”, "darse la paliza" o "darse el palo"... El vocabulario está en continua renovación: "Súper fácil", "Mola mazo", "En plan de", "To flama",... La ambigüedad en el mensaje, es decir, el uso abusivo de términos indefinidos, pobres en información, con un significado muy amplio: "pillar" puede ser coger algo de droga, coger unas bebidas, ligar,... o "fichote" por "tirar los tejos" o ligar,... Adopción de terminología marginada: "papear" por comer, "currar" por trabajar,... Uso de apelativos: "tronco", "tío", "chaval", "colega", "tt"... Así en el plano léxico la generación más joven busca un vocabulario que le permita una identificación propia, mientras que las generaciones anteriores son más moderadas. Siempre consideramos a nuestros padres más conservadores de lo que nosotros somos, de la misma manera nuestros hijos nos consideran más conservadores y ellos se ven más liberales, es decir, cuando maduramos lo hacemos a la vez que nuestro lenguaje.

Llegamos a las diferencias diastráticas, el factor sexo en la mensajería electrónica ha dejado de tener importancia; ya no hay, entre los jóvenes, diferencias en el habla en las que la mujer tendían a usar variables consideradas más prestigiosas y han perdido la conciencia de que el habla masculina es en general menos cuidada. (En este chat Marta dice: "me meo" y Cristina escribe "te despollas"). Es indudable que siguen existiendo palabras más femeninas: "muy mono", "ideal" o "divino" o palabras más masculinas como "amiguetes"; sin embargo, en un chat común o de grupo tanto ellas como ellos utilizan el mismo vocabulario. Lo que se hace evidente es que las barreras intersexuales son más acusadas dependiendo de la edad y en sociedades con mayor estratificación sociocultural. Hemos de recordar que los miembros pertenecientes a un grupo étnico determinado, también desarrollan un comportamiento lingüístico diferente y propio. Comportamiento que en numerosas ocasiones va asociado, en caso de existir, de un curioso sentimiento de fidelidad grupal que nace entre ellos, y hace que estos individuos no utilicen fórmulas normativas a pesar de conocerlas. 


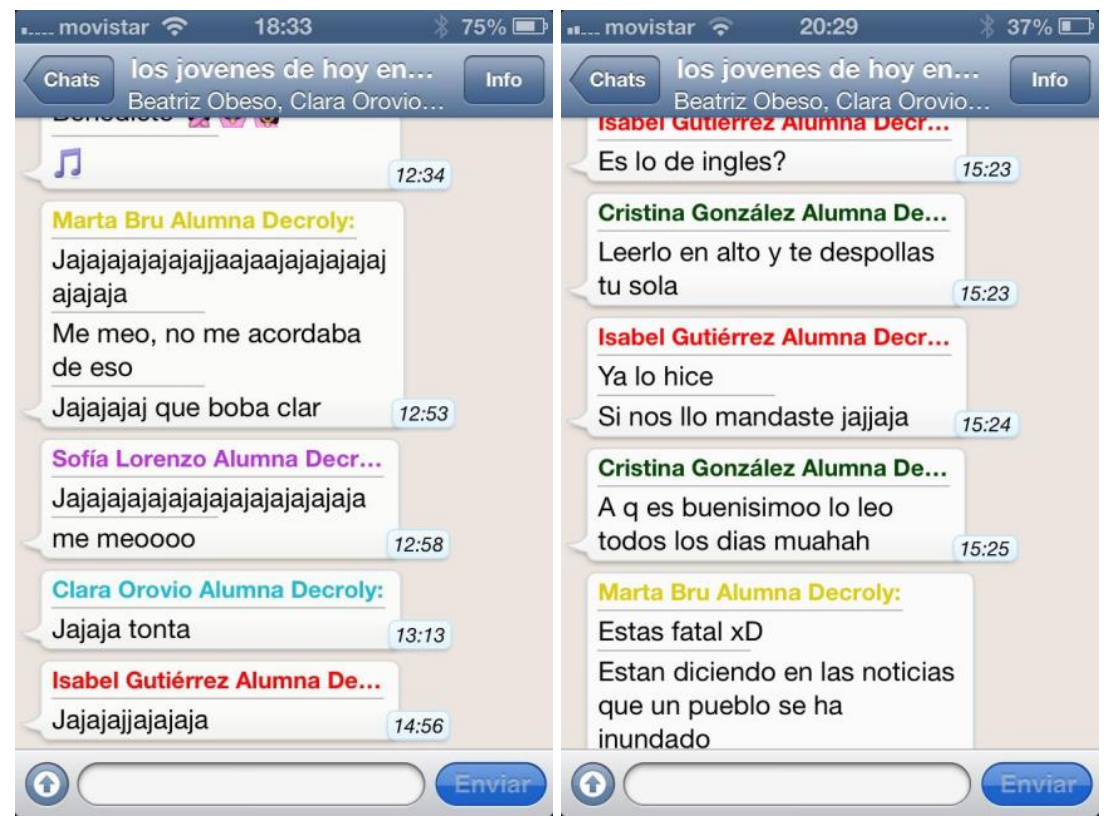

\section{EL CHAT EN EL AULA}

Para trabajar la competencia en comunicación lingüística y la competencia digital, hemos considerado el acceso y el empleo de las herramientas TIC en el aula (incorporar los chats, tanto de WhatsApp como foros en plataformas educativas como Moodle o Blackboard) en algunas actividades de la asignatura Lengua castellana y Literatura y emplearla en el aula universitaria en la asignatura de Didáctica de la Lengua. El objetivo fundamental, en el aula de secundaria y bachillerato, es que el alumno distinga la correcta expresión y la norma ortográfica, a través de foros y blogs. Es necesario que el alumno exprese sus sentimientos, emociones, dudas, inquietudes, conocimientos, formas de pensar, vivencias, opiniones y que se forme un juicio crítico y que sepa expresarlo de forma oral y por escrito. Es incuestionable que la tecnología forma parte fundamental de sus vidas, por lo que se hace necesario incluir en el aula los chats, los foros, las wikis, los blogs... El objetivo es enseñar a los alumnos a escribir y a expresarse con coherencia y corrección gramatical. En el aula universitaria, la asignatura es impartida a alumnos de magisterio, es allí donde se les enseña qué materiales se pueden crear y qué metodologías poner en práctica e incorporar en su futura docencia.

En ambos espacios hemos introducido chats como herramientas digitales, pero es en el aula de secundaria o bachillerato, donde trabajamos las expresiones, el vocabulario o la gramática que utilizan en un WhatsApp y la que utilizan en un foro o en el blog donde se van a publicar sus escritos. Hemos tenido en cuenta la necesidad de los jóvenes para comentar cualquier hecho, acontecimiento o circunstancia, 
por lo que se han propuesto temas, más o menos, interesantes para ellos. Al utilizar el WhatsApp no valoramos las incorrecciones ortográficas ni gramaticales, sino la rapidez de sus mensajes; después estos se trasladan a los foros donde ellos mismos corrigen su ortografía y su expresión. Por un lado, hemos trabajado la gramática, la coherencia y la cohesión; y por otro, según los temas que se proponen, su espíritu crítico. Con este planteamiento, el curso pasado los alumnos de $3^{\circ}$ de E.S.O publicaron un periódico, este año los alumnos de $3^{\circ}$ y $4^{\circ}$ siguen el mismo proyecto (http://estudiantes.elpais.com/periodico-papel/hemeroteca/Centro4770/Equipo376/ ver/index.html).

\section{CONCLUSIÓN}

Antes de terminar, quiero precisar que no podemos separar la forma de hablar que tienen los jóvenes con su momento en la historia, su presente. El punto de vista sincrónico señala un único periodo temporal, por eso, lo que hoy escriben esos jóvenes, solo lo harán mientras sean jóvenes. Ellos coexisten a la vez con la revolución tecnológica, con el habla propia de su generación y, con las características psicológicas de la juventud. Esta coincidencia de hechos en el tiempo hace que la escritura de los jóvenes en los chats tenga las particularidades que hemos comentado a lo largo de estas páginas. Pero hay un fenómeno más, y es que los jóvenes y adolescentes de este proyecto, que son alumnos universitarios, no coinciden en ese mismo tiempo, pues tienen ejes sincrónicos diferentes, con los adolescentes que estudian bachillerato, ni estos con los que estudian enseñanza secundaria. La escritura de los jóvenes en los chats debe ser entendida como una particularidad más propia de la edad que de la ignorancia. No significa, que en algunos casos, algunos alumnos no asimilen las reglas de ortografía y comentan los mismos errores en sus ejercicios escolares que en los chats. Los alumnos que nos ocupan se relacionan en un mismo horizonte temporal por lo que tienen las mismas influencias externas dentro del mismo espacio que es determinado y limitado. Evidentemente, el eje sincrónico ha de ir unido al diacrónico, por lo que la época en la que viven no se expresa en un punto único de los ejes. Es indiscutible que el tiempo es en sí mismo determinante para el cambio lingüístico, por lo que los jóvenes, esa comunidad lingüística, que se diferencia de otra comunidad lingüística por su habla, especialmente en el vocabulario y en la gramática, ignoran, bien porque no les interesa, bien por auténtico desconocimiento, que el vocabulario, las expresiones coloquiales que ellos utilizan como las más modernas y novedosas terminarán desapareciendo en el eje diacrónico con el paso del tiempo.

Este es el sugestivo mundo de internet; sabemos, indiscutiblemente, que es la revolución tecnológica más increíble de las últimas décadas. No me refiero al extraordinario invento tecnológico sino a que a finales de los 90 había en el mundo más de diez millones de ordenadores conectados, y hoy en día hay unos doce mil millones de dispositivos con conexión a internet, según la empresa investigadora de mercados IMS Research. La revolución es que millones de personas estén donde estén 
pueden comunicarse de forma inmediata, de que los buscadores en segundos son capaces de resolver cualquier duda, de que se puede "colgar" una imagen, un vídeo y miles de personas pueden verlo al instante. La facilidad de acceder a internet con los teléfonos móviles, ipads, tabletas android con $3 \mathrm{G}$ o por medio de wifi, gratuita cada vez en más lugares, hacen que la comunicación sea muy fluida a pesar de las distancias. Esa celeridad de los mensajes, esa necesidad de contestar inmediatamente una conversación por WhatsApp por parte de los jóvenes hacen que se rompan las reglas gramaticales y lo que se priorice sea la comunicación.

Por lo tanto, entiendo que no es inquietante que los jóvenes tengan una forma particular de escribir en los chats, sería inquietante que trasladaran esa forma de escribir a su vida académica. Los jóvenes con los que hemos contado para este trabajo saben cuáles son las reglas ortográficas y si no las usan es porque no les interesa en ese momento; bien porque tienen prisa, bien porque saben que su interlocutor entiende su mensaje. Este grupo de alumnos es un modelo que pone de manifiesto que hay jóvenes y adolescentes, con las mismas características, que conocen las normas lingüísticas y que los códigos de sus mensajes de chats son una moda pasajera que se irá a medida que se vayan haciendo adultos.

\section{BIBLIOGRAFÍA}

BLANCO RODRÍGUEZ, Ma José (2002): "El chat: la conversación escrita", en ELUA Estudios de Lingüística Aplicada, 16, Alicante, Universidad de Alicante, 43-87.

BONVÍN FAURA, Marcos Andrés (1997): Manual de errores lingüísticos. Barcelona, Octaedro.

CEBRIÁN, José Luis (1998): La red, Madrid, Taurus.

CRYSTAL, David (2001): Language and the Internet. Cambridge, Cambridge University Press.

LÓPEZ QUERO, Salvador (2003): El lenguaje de los “chats”. Aspectos gramaticales. Granada, Port-Royal Ediciones (Lingüística).

STRATEGY ANALYTICS: https://www.strategyanalytics.com [consulta: 9 noviembre 2015].

Yus, Francisco (2001): Ciberpragmática: el uso del lenguaje en Internet. Barcelona, Ariel. 